\title{
Minerais, mines, minéralurgie en Haute-Marne
}

\section{Yohann Thomas}

URL : http://journals.openedition.org/adlfi/11217

ISSN : 2114-0502

Éditeur

Ministère de la culture

Référence électronique

Yohann Thomas, « Minerais, mines, minéralurgie en Haute-Marne », ADLFI. Archéologie de la France Informations [En ligne], Champagne-Ardenne, mis en ligne le 01 mars 2004, consulté le 19 avril 2019. URL : http://journals.openedition.org/adlfi/11217

Ce document a été généré automatiquement le 19 avril 2019

(C) Ministère de la Culture et de la Communication, CNRS 


\title{
Minerais, mines, minéralurgie en Haute-Marne
}

\author{
Yohann Thomas
}

Identifiant de l'opération archéologique : 4850

Date de l'opération : 2004 (PC)

1 L'exploitation des minières de Poissons est connue depuis au moins le XVII ${ }^{\mathrm{e}}$ s., à en juger par un extrait de l'inventaire des titres et chartes de la seigneurie de Poissons, dépendant de l'abbaye de Saint-Urbain, daté du 8 octobre 1693. D'après ce document, les religieux prétendaient «qu'en leur qualité de seuls hauts justiciers, le sol par quintal de minerai leur appartenait, attendu que depuis plus de trente ans ce minerai avait été non seulement tiré et fouillé dans les bois d'usage communs, mais encore dans les terres abandonnées qui de droit doivent être selon la coutume, et réunies au domaine de la dite seigneurie ».

$2 \mathrm{Au} \mathrm{XIXe} \mathrm{s.} \mathrm{un} \mathrm{rapport} \mathrm{de} \mathrm{l'ingénieur} \mathrm{des} \mathrm{Mines} \mathrm{sur} \mathrm{la} \mathrm{régularisation} \mathrm{des} \mathrm{minières}$ communales de Montreuil-sur-Thonnance et de Poissons établit que ce minerai gît en amas à la partie supérieure des coteaux dans les dépressions du calcaire jurassique en couches horizontales. L'exploitation se fait alors, non par puits, mais par grandes excavations isolées les unes des autres de $10 \mathrm{~m}, 20 \mathrm{~m}$ et quelquefois $25 \mathrm{~m}$ de profondeur, "d'où le minerai est élevé péniblement à dos, au moyen d'échelles et de hottes, dont la forme est celle de la cavité naturelle qu'il remplit avec l'argile qui lui sert de gangue ».

3 À partir de 1859, de nouvelles zones minières sont investies, avec la réserve de la forêt communale de Poissons et le 17 mai 1862, divers maîtres de forges obtiennent autorisation d'extraire du minerai de fer dans la forêt communale sur une étendue de 10 hectares 5 ares 35 centiares (ceux de Thonnance-les-Moulins, Poissons, Noncourt, des Prés Bas près de Poissons, Thonnance-les-Joinville). 
4 En 1878, les minières des hauts plateaux de Poissons et de Montreuil sont exploitées à la comtoise, c'est-à-dire par petits puits peu durables, avec enlèvement du minerai à l'entour de ce puits jusqu'à une distance très variable, suivant la solidité du toit et la puissance du gisement. Mais elles semblent délaissées, malgré l'excellente qualité des minerais, à cause des profondeurs de $30 \mathrm{~m}$ et plus où il faut aller chercher la mine. En 1879, l'exploitation reste faible. L'extraction se fait sur deux points principaux, au bois de Châtillon, près de Thonnance-les-Joinville et à Montreuil-sur-Thonnance.

5 Les minerais étaient traités dans trois ateliers de lavage pour être réduits dans les hauts fourneaux de Bussy, du Rongeant et de Pancey. L'extraction totale était d'environ $6000 \mathrm{t}$ de minerai brut.

6 En 1885, on continue à extraire du minerai de fer dans des puits déjà pratiqués dans les bois dont la commune est propriétaire, à proximité du chemin de Poissons à Montreuilsur-Thonnance.

7 Les travaux de prospections réalisés dans le cadre du PCR se sont poursuivis sur le district ferrifère de Poissons, incluant les communes de Montreuil, Poissons, Noncourt et Thonnance, notamment sur le plateau qui domine la vallée du Rongeant et afin de retrouver d'autres exploitations souterraines. Les prospections au sol ont permis de découvrir un nouveau gouffre mine (le gouffre de la Cigale) sur la commune de Poissons (Fig. $n^{\circ} 1$ : Minière de la cigale : méandre karstique entièrement vidé. Présence de boisage en place (commune de Poissons)) .

8 Ce gouffre mine présente toutes les caractéristiques d'une exploitation karstique par vidage. Il s'agit d'un méandre vertical, dont les mineurs ont exploité le remplissage en installant des chantiers mobiles à partir de billes de bois serrées sur les parois (Fig. $\mathrm{n}^{\circ} 2$ : Topographie de la minière de la Cigale (commune de Poissons) ) .

9 Les prospections menées sur le revers de côte n'ont pas donné les résultats escomptés en matière de sites souterrains. Seules les excavations à ciel ouvert dominent dans les zones boisées. Dans la forêt de Montreuil ont été repérés les vestiges d'un abornement minier. Les bornes de section quadrangulaire se distinguent nettement des bornes classiques liées à l'exploitation forestière. Il pourrait s'agir d'un abornement minier ancien de concessions lié à l'exploitation des mines par les moines de Poissons.

10 Une tranchée de recherche moderne, effectuée par un agriculteur en vue de capter d'éventuelles nappes souterraines, a permis d'observer et de relever une coupe stratigraphique de remplissage karstique comportant des minerais de fer en plaquette et géodiques. Ce secteur dit de la Houppette est localisé au cœur d'une importante concentration de minières à ciel ouvert, correspondant à l'exploitation d'un lapiaz fossile.

11 Une prospection aérienne réalisée en hiver 2004 complète le dispositif de prospection au sol (Fig. n³: Photographie aérienne des minières de Mélaire (commune de Poissons)) . Elle a permis d'identifier un certain nombre de vestiges liés au lavage du minerai notamment au niveau des thalwegs.

12 Au nord de Joinville, plusieurs ferriers associés à des charbonnières ont été identifiés par la prospection aérienne.

13 Nous avions déjà repéré ici ou là quelques indices de réduction sous la forme de scories, notamment dans les environs de Châtonrupt ou de Poissons. Cette année, les hasards de la prospection ont permis de découvrir des indices probants de métallurgie ancienne de réduction directe, notamment à Noncourt et Châtonrupt à proximité immédiate de zones 
d'extraction encore parfaitement conservées. La liaison entre site de réduction et site d'extraction ne fait guère de doute sur ces deux sites.

À Noncourt, une première datation ${ }^{14} \mathrm{C}$ donne une date gallo-romaine (III ${ }^{\mathrm{e}} \mathrm{s}$.-IV ${ }^{\mathrm{e}} \mathrm{s}$.) pour les charbons de bois recueillis sur place.

Les travaux agricoles profonds minent chaque année un peu plus le site, dans une zone où le remplissage n'est guère important. Le substrat calcaire y affleure en effet à maints endroits. Une fouille de sauvetage ou le gel du site serait souhaitable. À Morancourt les concentrations de scories se trouvent directement dans une zone d'extraction parfaitement mise en évidence au cours de la prospection. Il s'agit d'une découverte majeure concernant l'ancienneté de l'occupation et de l'extraction dans cette région de Haute-Marne.

16 À Pont Varin, les prospections n'ont pas permis de retrouver d'accès potentiel au milieu souterrain. Les minières et carrières à ciel ouvert marquent le paysage de cette zone. Un certain nombre de vestiges liés au transport du minerai ont été mis en évidence sous couvert forestier: canaux, trémies, chemins d'accès, sans toutefois déceler d'éventuels orifices. Les vestiges au sol concernent essentiellement la période la plus récente de l'exploitation.

17 Parmi les constructions encore visibles : les tronçons du canal de Wassy à Saint-Dizier, les soubassements de l'estacade de déchargement sur les péniches, à Pont Varin, quelques écluses et les maçonneries de supports de machineries des usines du Châtelier et du Buisson. La levée, qui supportait la voie ferrée qui conduisait les wagonnets de minerai à l'estacade de Pont Varin est encore visible, mais les voies ont été enlevées. Quant aux zones d'extraction situées aux lieux-dits Les Cantines de part et d'autre de la D. 261, les minières, situées sur le finage de Voillecomte, Les Ecrues et Petits Hayeux, présentent toutes une exploitation à ciel ouvert. La profondeur moyenne des minières est de $4 \mathrm{~m}$ à $5 \mathrm{~m}$, mais sans recéler de galerie. La tradition orale indique que les extractions à ciel ouvert étaient majoritaires sur l'ensemble de la zone de Wassy, Pont Varin, Allichamps, Louvemont, Bailly aux Forges, Laneville à Rémy ou Voillecomte.

Denis JACQUEMOT, Denis MORIN, Hélène MORIN-HAMON, Denis SCHMITTER

\section{ANNEXES}


Fig. $n^{\circ} 1$ : Minière de la cigale : méandre karstique entièrement vidé. Présence de boisage en place (commune de Poissons)

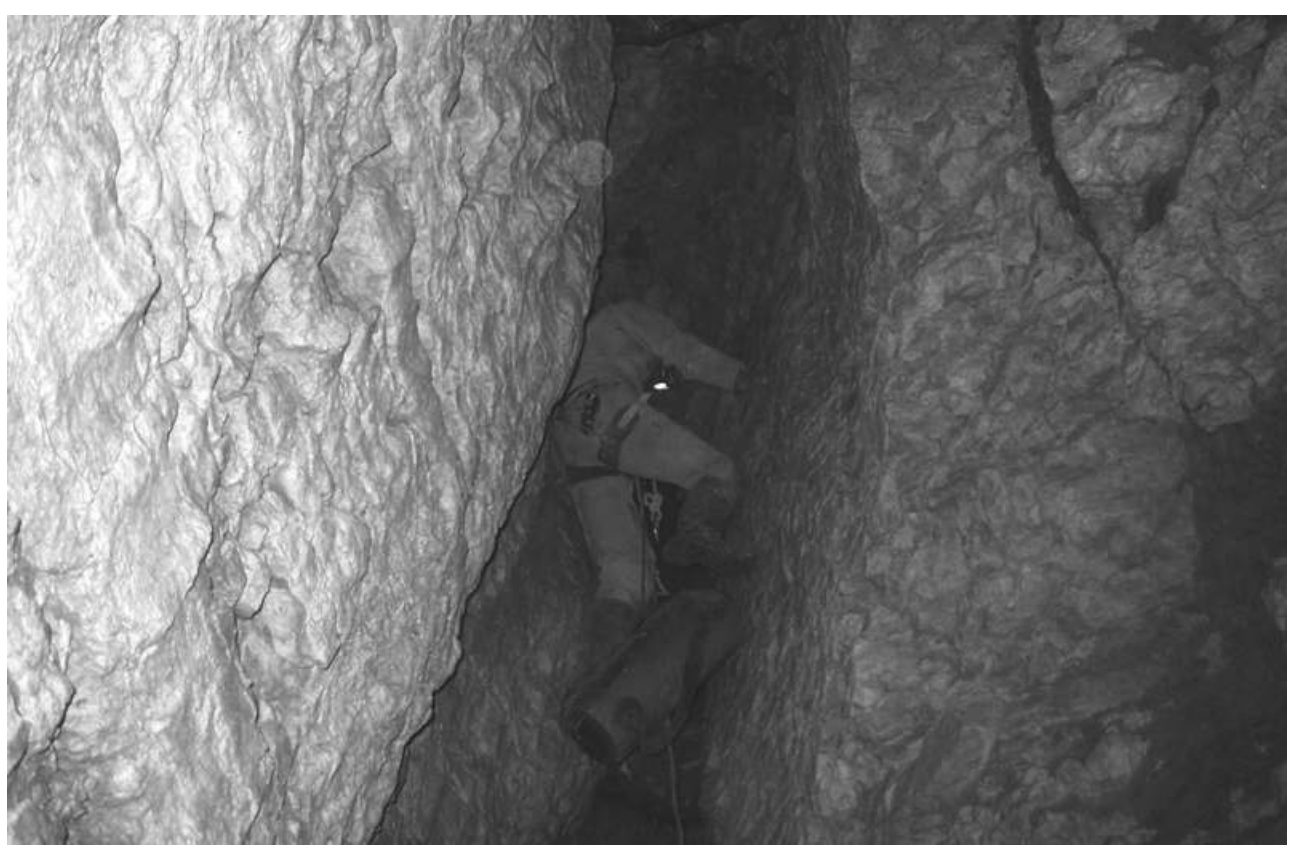

Auteur(s) : Jacquemot, Denis (BEN). Crédits : Jacquemot, Denis (2004)

Fig. $n^{\circ} 2$ : Topographie de la minière de la Cigale (commune de Poissons)

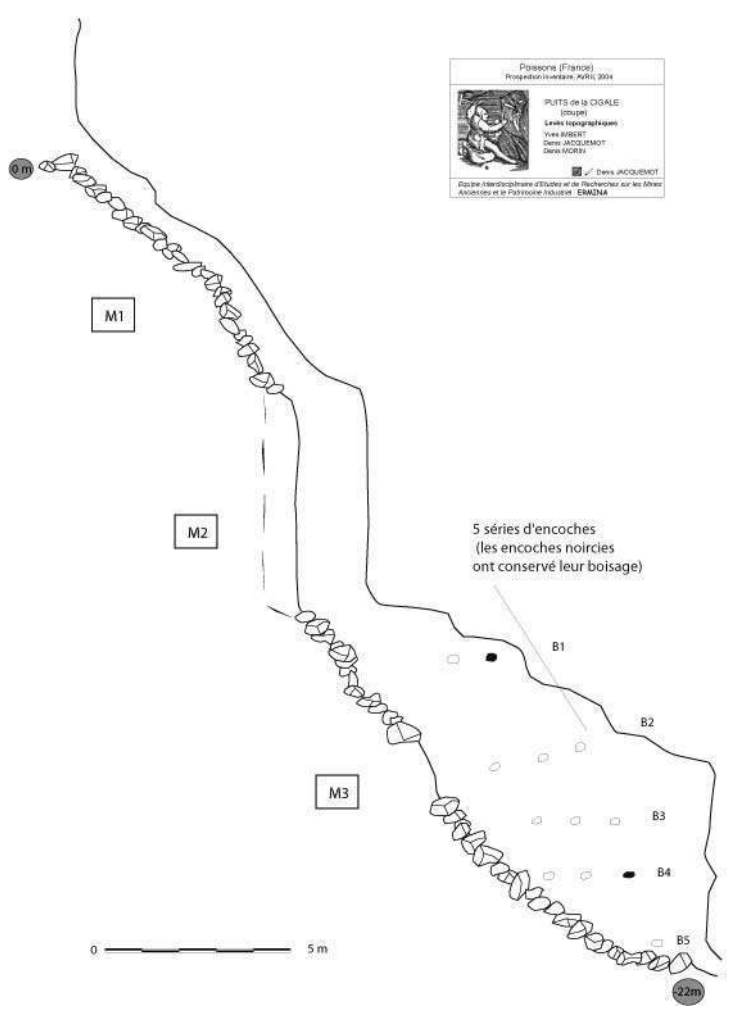

Jacquemot, Denis ; Imbert Yves ; Morin, Denis (2004) 
Fig. $n^{\circ} 3$ : Photographie aérienne des minières de Mélaire (commune de Poissons)

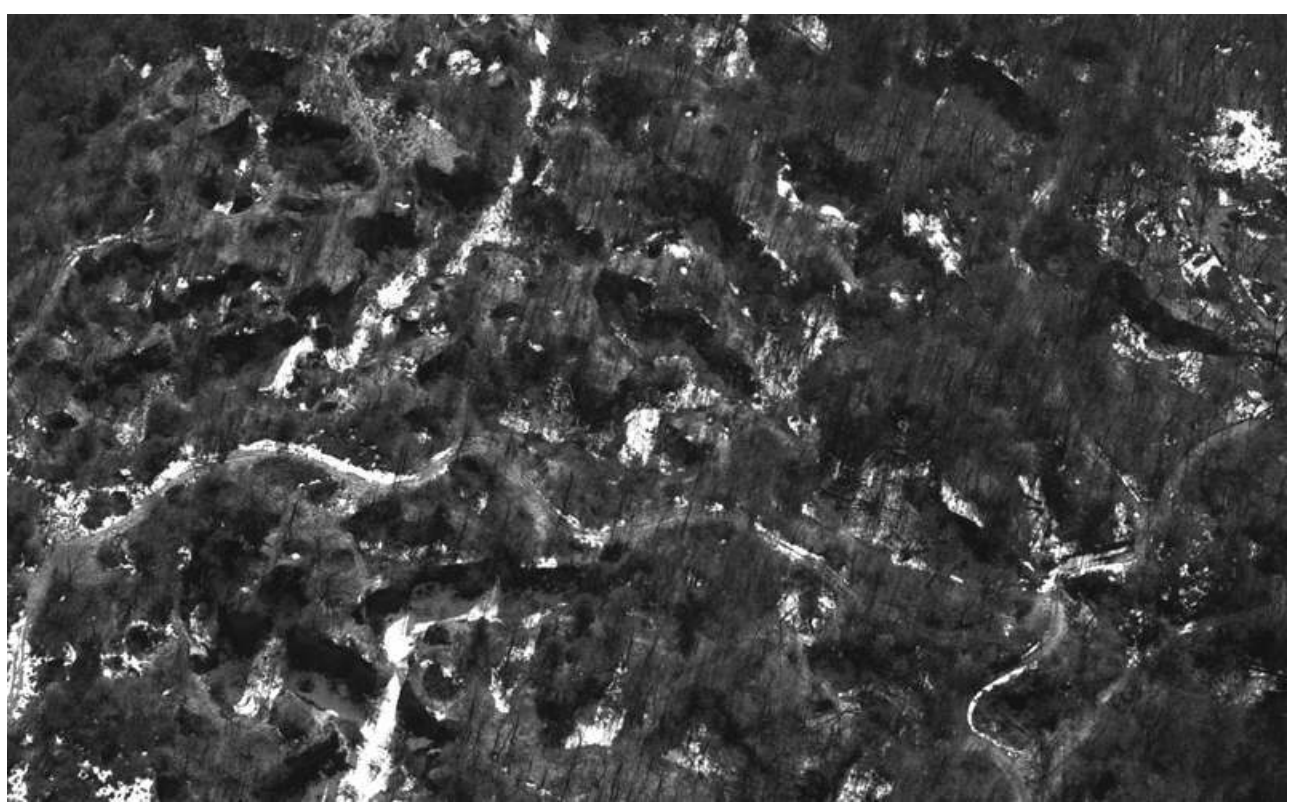

Auteur(s) : Jacquemot, Denis (BEN). Crédits : jacquemot Denis (2004)

INDEX

Index géographique : Champagne-Ardenne, Haute-Marne (52), Poissons

Thèmes : acquisition de ressource naturelle, aménagement de berge, bois d'œuvre, borne, canal, charbon de bois, fer, ferrier, forge, four, haut-fourneau, métallurgie, mine, minerai, prospection aérienne, scories, transport sur eau, transport sur terre

Index chronologique : Bas-Empire

operation Projet collectif de recherche (PCR)

\section{AUTEURS}

\section{YOHANN THOMAS}

INRAP 